\title{
A SOLUÇÃO DE FRAÇÃO: UM OLHAR SOBRE O MODO COMO PROFESSORES DOS ANOS INICIAIS RESOLVEM SITUAÇÕES QUE ENVOLVEM QUANTIDADES
}

\author{
THE FRACTION SOLUTION: A LOOK AT THE WAY HOW TEACHERS FROM THE \\ EARLY YEARS SOLVE SITUATIONS THAT INVOLVE QUANTITIES
}

\section{LA SOLUCIÓN DE FRACCIONES: UNA MIRADA A LA FORMA EN QUE LOS PROFESORES DE PRIMERA EDAD RESUELVEN SITUACIONES QUE INVOLUCRAN CANTIDADES}

\author{
IDEMAR VIZOLLI ${ }^{1}$ \\ MARCOS JOSÉ PEREIRA BARROS
}

\section{RESUMO}

Analisamos, neste artigo, o modo como professores que ensinam Matemática nos $4^{0}$ e $5^{\circ}$ Anos do Ensino Fundamental resolvem situações de fração que envolvem quantidades. A abordagem metodológica é qualitativa e exploratória, desenvolvida na fase de sondagem de um Curso de Formação Continuada, que contou com a participação de oitenta e oito professores, os quais resolveram atividades relacionadas ao conceito de fração, considerando seus significados, registros de representação semiótica e características das quantidades. As análises consideraram o processo pelo qual os professores resolveram situações de fração que envolvem quantidades contínuas, discretas, intensivas e extensivas. Os resultados indicam que as situações de fração que envolvem quantidades, requerem a compreensão do significado de produto, o que muitas vezes não é trivial para os professores. Estes por sua vez, apresentam facilidade em resolver situações que comportam a relação parte-todo, em tarefas que envolvem quantidades discretas e contínuas.

Palavras-chave: Educação. Professores de Anos Iniciais. Formação continuada. Fração. Características das quantidades.

\section{ABSTRACT}

In this article, we analyze how teachers who teach mathematics in the 4th and 5th years of elementary school solve fractional situations that involve quantities. The methodological approach is qualitative and exploratory, developed during the survey phase of a Continuing Education Course, which involved the participation of eighty-eight teachers, who solved activities related to the concept of fraction, considering their meanings, records of semiotic representation and characteristics of the quantities. The analyzes considered the process by which teachers resolved fractional situations that involve continuous, discrete, intensive and extensive quantities. The results indicate that fractional situations involving quantities require an understanding of the meaning of the product, which is often not trivial for teachers. These, in turn, have an ease in solving situations that involve the part-whole relationship, in tasks that involve discrete and continuous quantities.

Keywords: Education. Early Years Teachers. Ongoing training. Fraction. Characteristics of the quantities

\section{RESUMEN}

En este artículo analizamos cómo los docentes que imparten Matemáticas en $4^{\circ}$ y $5^{\circ}$ de primaria resuelven situaciones fraccionarias que involucran cantidades. El enfoque metodológico es cualitativo y exploratorio, desarrollado durante la

1 Doutor em Educação (UFPR). Docente do Programa de Pós-Graduação em Educação da Universidade Federal do Tocantins (PPGE-UFT). E-mail: idemar@mail.uft.edu.br. ORCID: https://orcid.org/0000-0002-7341-7099

2 Mestre em Educação (UFT). Docente na Secretaria Estadual de Educação do Tocantins (SEDUC-TO). E-mail: marcos.mat@uft.edu.br. ORCID: https://orcid.org/0000-0002-9387-0309 
fase de relevamiento de un Curso de Educación Continua, que contó con la participación de ochenta y ocho docentes, quienes resolvieron actividades relacionadas con el concepto de fracción, considerando sus significados, registros de representación semiótica y características de las cantidades. Los análisis consideraron el proceso mediante el cual los docentes resolvieron situaciones fraccionarias que involucran cantidades continuas, discretas, intensivas y extensivas. Los resultados indican que las situaciones fraccionarias que involucran cantidades requieren una comprensión del significado del producto, que a menudo no es trivial para los profesores. Estos, a su vez, tienen facilidad para resolver situaciones que involucran la relación parte-todo, en tareas que involucran cantidades discretas y continuas.

Palabras-clave: Educación. Profesores de Educación Infantil. Entrenamiento en curso. Fracción. Características de las cantidades.

\section{INTRODUÇÃO}

Tradicionalmente, os professores repassam o conteúdo por meio da representação parte-todo, na qual é utilizada a concepção de dupla contagem, que consiste em contar a quantidade de partes e sobrepor ao total de partes que um todo foi dividido, sobrepondo os números separados por um "tracinho". Segundo Schastai; Farias; Silva (2017), os professores iniciam a abordagem do conceito de fração fazendo uso de figuras geométricas planas, direcionando 0 ensino e a aprendizagem aos algoritmos. Neste sentido, os estudantes dividem o todo de acordo com o valor indicado no denominador da fração, destacando as partes indicadas no numerador. As autoras evidenciam que "o procedimento considerado adequado para representar as frações utilizando figuras geométricas planas é dividir o todo em partes iguais em relação à área" (SCHASTAl; FARIAS; SILVA, 2017, p. 74).

De acordo com Bessa (2007), na atuação de muitos professores da Educação Básica e até mesmo do ensino superior, muitas vezes, ainda prevalece o repasse do conteúdo de fração e o processo de solução via uso de algoritmos, regras ou macetes. Schastai; Farias; e Silva (2017, p. 45) entendem que os professores devem se desprender da prática pedagógica que tenha resquícios em uma racionalidade técnica. "Ele precisa ser um profissional que saiba articular o processo pedagógico com as necessidades dos alunos em sua vivência social e cultural" e seja capaz de motivar os estudantes a refletirem sobre 0 que estão fazendo. Em algumas situações, os professores recorrem ao Mínimo Múltiplo Comum (MMC) para somar e/ou subtrair frações e esquecem-se, por exemplo, que ao estudar frações que envolvem quantidades discretas (aquelas cujas unidades só podem ser concebidas em seu todo), pode-se recorrer à equivalência fracionária. A aprendizagem dos estudantes não pode decorrer de uma prática educativa que valorize somente 0 fazer e operar em detrimento do pensar e abstrair. Deve-se valorizar a capacidade que cada estudante tem de criar situações cuja finalidade é compreender aquilo que está sendo feito (SILVA, 2013).

0 ensino de Matemática não deve se esquivar de sua função social e os "estudos das frações não podem ser deixados como um estudo opcional. Há de se compreender que elas fazem parte do nosso cotidiano, isto é, estão presentes nas atividades mais comuns como em receitas culinárias, e, portanto, não são desconhecidas pelos alunos" (SILVA, 2013, p. 18).

Entende-se que as pesquisas em relação ao modo como os professores resolvem situações que envolvem fração poderão trazer contribuições aos processos de ensino e aprendizagem de fração nos anos iniciais do Ensino Fundamental. Dessa forma, foi elaborado um projeto amplo em que se estuda os processos de ensino e aprendizagem de fração, do qual deriva uma série de pesquisas de professores e estudantes do Curso de Mestrado em Educação da Universidade Federal do 
Tocantins (UFT). Integrando o projeto mais amplo, tem-se a oferta de um curso de formação continuada para professores de $4^{\circ}$ e $5^{\circ}$ Anos do Ensino Fundamental da rede municipal de Araguaína, TO.

0 escopo de uma das pesquisas realizadas no curso de formação continuada, situa-se no modo como os professores resolvem situações de fração, contemplando seus cinco significados, 0 uso de registros de representação semiótica, características das quantidades, bem como equivalência e comparação de frações. Este artigo é um recorte desta pesquisa e tem como objetivo analisar 0 modo como professores que ensinam Matemática nos $4^{\circ}$ e $5^{\circ}$ Anos do Ensino Fundamental resolvem situações de fração que envolvem quantidades contínuas, discretas, intensivas e extensivas.

Trata-se de um estudo de natureza qualitativa e exploratória, cuja preocupação reside em descrever minuciosamente a situação, especialmente porque se quer captar a ideia em relação ao modo como os participantes solucionaram as atividades. Estes, de posse das atividades, ficaram livres para respondê-las e foram orientados a efetuarem registros dos procedimentos utilizados.

Para Araújo (2009, p. 55) na pesquisa qualitativa "é necessário utilizar instrumentos e procedimentos específicos, que garantam uma descrição confiável e desejável de todos os passos da pesquisa. 0 delineamento, a coleta, a transcrição e análise dos dados fazem parte esse desenvolvimento". Já Silveira e Córdova (2009, p. 32) consideram que o pesquisador se torna tanto 0 sujeito quanto objeto de suas pesquisas e o desenvolvimento dela é imprevisível. "O conhecimento do pesquisador é parcial e limitado. 0 objetivo da amostra é de produzir informações aprofundadas e ilustrativas: seja ela pequena ou grande, o que importa é que ela seja capaz de produzir novas informações".

Nestes termos o pesquisador não está focado somente quantificar erros e/ou acertos dos participantes, mas em descrever, compreender e explicar os dados coletados, relacionando-os às dinâmicas da sociedade. Dentre suas características destacamos "busca de resultados os mais fidedignos possíveis; oposição ao pressuposto que defende um modelo único de pesquisa para todas as ciências" (SILVEIRA; CÓRDOVA, 2009, p. 32).

0 desenvolvimento da pesquisa contou com um conjunto de cinco atividades, constituídas por tarefas, as quais contemplaram os significados de fração, 0 uso de diferentes registros de representação semiótica, características das quantidades, equivalência e comparação de fração. Neste artigo damos atenção às tarefas que envolvem quantidades (contínuas, discretas, intensivas e extensivas).

Os professores foram organizados em seis grupos, de modo que cada um resolvesse um conjunto de tarefas. Participaram da pesquisa oitenta e oito professores que ensinam Matemática nos $4^{0}$ e $5^{\circ}$ Anos do Ensino Fundamental da rede municipal de ensino de Araguaína, T0 (dos professores). Registra-se que o estudo contou com anuência do Comitê de Ética em Pesquisa (CEP) e que os participantes puderam optar para serem identificados pelos respectivos nomes ou por pseudônimos. Para os que optaram por pseudônimos, atribuímos-lhe nomes de matemáticos consagrados.

\section{ALGUNS ASPECTOS EM RELAÇÃO A FORMAÇÃO DE PROFESSORES}

De acordo com Schastai; Farias; Silva (2017, p. 15), nos últimos anos, tem crescido o número de pesquisas sobre a temática da formação de professores em todo o mundo, de modo que "os professores passam a ser considerados mediadores no processo de formação de cidadãos, na superação dos fracassos escolares e na redução das desigualdades sociais".

Para Tardif (2014, p. 33-34), "enquanto grupo social, em virtude das próprias funções que exercem, os professores ocupam uma posição estratégica no interior das relações complexas que unem as sociedades contemporâneas aos saberes que elas produzem e mobilizam com diversos fins". 
Essa posição estratégica está voltada para a produção do conhecimento e a formação do estudante imbuído de aspectos científicos e de uma postura crítica e participativa na sociedade. Assim, os professores devem tomar para si a responsabilidade de proporcionar aprendizagem coletiva e individual, cujo objetivo esteja constituído de uma cultura intelectual e científica.

0 professor deve efetivar sua prática por meio de investigações e análises da realidade "e vinculações entre as práticas educativas e as práticas sócio-culturais, objetivando a reconstrução de uma práxis educativa democrática e cidadã, bem como a melhoria do processo ensino-aprendizagem e das relações interpessoais". Os profissionais na área da Matemática deveriam assumir essa postura de formação crítica e participativa dos estudantes, tanto em ambientes escolares, quanto no meio social (BESSA, 2007, p. 31). De acordo com os Parâmetros Curriculares Nacionais (PCN)

A aprendizagem em Matemática está ligada à compreensão, isto é, à apreensão do significado; apreender 0 significado de um objeto ou acontecimento pressupõe vê-lo em suas relações com outros objetos e acontecimentos. Assim, o tratamento dos conteúdos em compartimentos estanques e numa rígida sucessão linear deve dar lugar a uma abordagem em que as conexões sejam favorecidas e destacadas. 0 significado da Matemática para 0 aluno resulta das conexões que ele estabelece entre ela e as demais disciplinas, entre ela e seu cotidiano e das conexões que ele estabelece entre os diferentes temas matemáticos. (BRASIL, 1997, p. 19).

0 ensino da Matemática deve conduzir os estudantes a compreenderem que essa ciência não está isolada das demais, e que aprender determinado significado de um objeto, pode levá-los a estabelecer relações com outros objetos e acontecimentos. "Esse é um importante processo, pois dele depende a agilidade e a facilidade na realização de cálculos mentais, necessários para o desenvolvimento progressivo da matemática nos anos iniciais e finais do Ensino Fundamental, no Ensino Médio e na Educação Superior" (BESSA, 2007, p. 33).

Silva (2013, p. 17), assevera "que os problemas de aprendizagem que os alunos enfrentam para a formação de conceitos sejam decorrentes de uma prática mecanicista, que valoriza excessivamente 0 'fazer' e 0 'operar' e desconsidera a importância do pensar e do abstrair". Esse tipo de abordagem influencia os estudantes a criarem aversão à Matemática. Concebe-se um mito de que ela é muito difícil e complicada, acessível apenas aos "gênios".

É importante ensinar o conceito de fração, dedicando mais atenção a atividades de resolução de problemas que envolvem 0 cotidiano dos estudantes de maneira contextualizada, 0 que demanda dos professores, estar em constante atualização profissional. "Desta forma, o ensino passa a ser mediado por situações didáticas que contextualizem as experiências prévias do aluno, e possibilitam uma aprendizagem significativa" (LIMA, 2014, p. 76).

De acordo com Schastai; Farias; Silva (2017), os professores possuem uma tendência a inserir 0 que aprenderam nas formações, em suas práticas em sala de aula. Ao se tornar um sujeito reflexivo, que vivencia diferentes maneiras de ensinar determinado conteúdo matemático, o professor será capaz de conduzir os estudantes a desempenharem papel ativo e participativo nos processos de ensino e aprendizagem, o que favorece a compreensão de conceitos.

Durante a formação inicial do professor que ensina Matemática, geralmente, não se aprende a apropriar-se do conhecimento, mas a recebê-lo. Assim, ao ministrar suas aulas, a preocupação fica concentrada na prática matemática, e não na prática do professor que ensina Matemática. A 
"formação do pedagogo - professor que atua nos anos iniciais - concentra-se muito no 'como fazer', considerando princípios metodológicos e didáticos, e carece de conteúdo específico para o ensino das áreas do conhecimento" (SCHASTAl; FARIAS; SILVA, 2017, p. 19).

Além de educador e mediador do conhecimento, o professor deve assumir o papel de pesquisador da sua própria prática, ou seja, refletir sobre a sua ação pedagógica. Dessa forma, de acordo com Pinheiro (2014, p. 32), "0 professor torna-se capaz de refletir criticamente sobre as dificuldades enfrentadas tanto em relação ao ensino quanto à aprendizagem de conteúdos, e no nosso caso específico, do conteúdo frações". 0 autor sustenta que pesquisar e refletir sobre os motivos pelos quais levaram os estudantes a responderem determinada atividade, ou de que forma eles pensaram, no intuito de encontrar a solução da situação proposta, pode fazer com que o professor repense sua prática educativa ao ensinar, bem como o modo com que os estudantes aprendem. Tal situação mostra que a formação de professores "deve criar estratégias facilitadoras sobre a prática e na prática do professor e que deve contemplar os aspectos do cotidiano para que esse profissional possa repensar e reconstruir a própria prática e ter condições de buscar o devido desenvolvimento profissional" (CERVANTES, 2011, p. 11).

Situações como essa apontam para a necessidade de comprometimento por parte das instituições de ensino superior, especialmente nos cursos de Pedagogia e Matemática, que devem conferir mais atenção aos processos de ensino e aprendizagem de Matemática e, nela, o de fração. Uma vez que "podemos também inferir que tais graduações não estão contemplando a formação inicial que garanta ao professor 0 seu sucesso com o ensino de frações, implicando diretamente no fracasso dos alunos sobre 0 assunto" (SILVA, 2013, p. 143). Segundo Schastai; Farias; Silva (2017, p. 22) há uma lacuna na "formação acadêmica dos professores que, presos aos livros didáticos, limitam-se a trabalhar com figuras geométricas divididas igualmente". Esse panorama indica que os professores precisam conhecer os diferentes significados que a fração comporta, assim como as características das quantidades.

\section{Significados de fração}

Segundo Nunes et al. (2003 apud MERLINI, 2005), a classificação teórica do conceito de fração contempla cinco significados, a saber: número, parte-todo, medida, quociente e operador multiplicativo. "Consideramos que é importante conhecer as diferentes ideias das frações porque essas têm relação com a construção do conceito de números fracionários" (SCHASTAI; FARIAS; SILVA, 2017, p. 87).

No significado parte-todo "a ideia presente nesse significado é a da partição de um todo (contínuo ou discreto) em partes iguais e que cada parte pode ser representada como $\frac{1}{n}$ " (MERLINI, 2005, p. 28).

0 significado número se refere ao fato de que a fração não precisa necessariamente remeter a uma determinada quantidade (contínua ou discreta). E, ao compreender que a fração é um número, "existem duas formas de representação fracionária, a ordinária e a decimal" (MERLINI, 2005, p. 27). Assim, o sujeito não precisa recorrer às situações particulares no contexto das quantidades contínuas e/ou discretas para compreender e resolver problemas de conversão decimal em fracionária.

Já o significado medida, está associado à ideia de comparação entre duas quantidades (intensivas e extensivas), sendo que algumas medidas são obtidas por meio da relação entre variáveis, em outros termos, esse significado está ligado à identificação de quantas vezes uma unidade "cabe" em outra e qual fração corresponde a essa comparação.

0 significado quociente está presente nas situações em que a operação de divisão se torna uma estratégia eficaz na resolução de uma determinada situação problema. "Isso significa que conhecido 0 número do grupo a ser formado, o quociente representa o tamanho de cada grupo" (MERLINI, 2005, p. 30). 
0 significado operador multiplicativo está associado ao papel de transformação, isto é, "a representação de uma ação que se deve imprimir sobre um número ou uma quantidade, transformando seu valor nesse processo" (MERLINI, 2005, p. 31). As situações que mobilizam essa concepção, consideram que frações são tidas como números, e compreendidas com operações de multiplicação dos fracionários com as quantidades consideradas. Ou seja, a ação do operador multiplicativo modifica um estado inicial, produzindo um estado final (SILVA, 2005).

Considerando os apontamentos, serão exemplificadas algumas maneiras de abordagem de $\frac{2}{5}$, a fim de que se tenha maior clareza quanto aos significados de fração: (a) número - $\frac{2}{5}$ é um número, como os inteiros, e pode ser colocado sobre uma reta numérica ou comparado com outro (ordenação); (b) parte-todo - um inteiro dividido em cinco partes iguais, sendo tomadas duas delas; (c) medida - em determinada medida foram tomadas duas unidades de medidas de $\frac{1}{5}$; (d) quociente - divisão de 2 por 5 ; (e) operador multiplicativo - considera-se uma medida, número ou grandeza e calculam-se dois quintos por meio de um produto.

É necessário que os professores possam distinguir as características das quantidades bastante presentes em situações didáticas que envolvem fração.

\section{Quantidades contínuas e discretas, intensivas e extensivas}

Especialmente no ensino do conceito de números racionais, o entendimento e 0 domínio a respeito das características das quantidades é fundamental para a sua compreensão. Não raro, professores da Educação Básica e até mesmo os do Ensino Superior, usam o conceito de fração entendendo-0, como uma quantidade discreta.

Quando compreendemos as características das quantidades e conseguimos diferenciar quantidades contínuas e discretas, intensivas e extensivas, os processos de ensino e aprendizagem do conceito de fração pode se tornar mais significativo, tanto para o professor quanto para 0 estudante (NUNES et al., 2005; MERLINI, 2005; CARVALHO, 2017).

Desse modo, entende-se que quantidade discreta é um conjunto de objetos de mesma natureza (ou unidades naturais) que, mesmo depois de realizar algum tipo de operação matemática, formam um novo conjunto ou subconjuntos, mantendo-se as mesmas características iniciais. Isto é , dizem respeito a um conjunto de objetos idênticos, que representam um único todo e o resultado da divisão deve produzir subconjuntos com o mesmo número de unidades. Exemplo: João tinha quinze bolinhas de gude, jogou com seu amigo José e ganhou três bolinhas. Com quantas bolinhas João ficou depois de ter jogado? Assim, as unidades naturais são características que definem uma quantidade discreta. São exemplos de unidades naturais: três botões, quatro tijolos, dez bonés, quinze bolinhas de gude, conjuntos de pessoas, votos, e assim por diante. Enfim, independentemente da quantidade de unidades que se considere, elas terão a mesma natureza e continuarão sendo unidade de objeto (NUNES et al., 2005).

As quantidades contínuas são aquelas que podem ser divididas exaustivamente sem que percam suas características iniciais, o que é típico no caso das medidas, por exemplo. Trata-se de unidades convencionais (dois metros, três quilos, um litro, ...), as quais muitas vezes contam com subunidades mantendo as mesmas características $(1,3 \mathrm{~m}=130 \mathrm{~cm}=1300 \mathrm{~mm} ; 1,5 \mathrm{~kg}=1500 \mathrm{~g}$; $0,75 \mathrm{I}=750 \mathrm{ml}$ ). Isso significa que, ao se tomar uma unidade padrão, é possível que as demais medidas sejam comparadas. As unidades convencionais, como o comprimento de uma mesa, o peso de algum objeto, a quantidade de água em uma limonada, por exemplo, são características de quantidades contínuas. É interessante registrar que é possível ainda estabelecer relação entre unidades de 
medidas convencionais e não convencionais, sem que se perca as características que as conceituem. Nesse caso podemos efetuar medidas de comprimento fazendo uso de partes do corpo como por exemplo, palmos, pés, dentre outros (NUNES et al., 2005)

Apesar das diferenças entre quantidades contínuas e descontínuas, elas estão baseadas na mesma estrutura lógica, que é a relação parte-todo: a soma das unidades é igual ao valor do todo. Essa estrutura lógica relaciona-se ao fato de que a medida dessas quantidades é essencialmente uma comparação entre duas quantidades de mesma natureza (NUNES et al., 2005, p. 121).

Nesse sentido, ao se comparar "três metros" com o comprimento de uma mesa, e "uma bolinha de gude" com o conjunto de bolas de gude, por exemplo, estamos tratando de quantidades de mesma natureza comparadas entre si. Há, portanto, uma comparação entre a unidade convencional "metro" com o comprimento da mesa e, "uma bolinha de gude" com um conjunto maior também de bolinhas de gude. Essas duas situações tratam de quantidades extensivas. De acordo com Nunes et al. (2005, p. 122), "quando a medida de uma quantidade se baseia na comparação de duas quantidades da mesma natureza e na lógica parte-todo, dizemos que a medida se refere a uma quantidade extensiva." Ao se comparar quantidades distintas de uma mesma substância sem alterar suas características iniciais estamos diante de quantidades extensivas.

Consideremos uma jarra e tomemos dois recipientes menores (ambos estão com suco de laranja) com capacidades de $80 \mathrm{ml} \mathrm{e} 20 \mathrm{ml}$ respectivamente, e colocamos tudo na jarra de suco. Qual a quantidade de suco na jarra? Nessa situação, estamos juntando duas quantidades de mesma natureza (suco de laranja) e formando um todo maior, ou seja, estamos usando o princípio aditivo, em que o todo (100 ml) é igual à soma das partes (80 $\mathrm{ml}$ e $20 \mathrm{ml})$; nesse caso, temos uma medida portanto temos quantidades extensivas e , ao mesmo tempo ainda uma quantidade contínua. (NUNES et al., 2005).

Observa-se a seguinte situação: "Temos suco de laranja com de suco concentrado numa vasiIha e em outra. Colocamos tudo numa vasilha maior. Qual a concentração do suco na vasilha maior?" (NUNES et al., 2005, p. 122). Temos duas vasilhas com concentrações de suco diferentes (80\% e $20 \%$ ), mas quando as juntamos em um recipiente maior, a concentração de suco não permanece a mesma e nem chega a 100\% (suco puro). Nesse caso, ao misturar sucos com concentrações distintas, tem-se um suco com a fusão das concentrações, logo, uma nova concentração distinta daquelas de partida. Tem-se uma vasilha com oitenta partes de suco concentrado para vinte partes de água e em outra há vinte partes de suco concentrado para oitenta partes de água. Portanto, estamos tratando de quantidades contínuas e intensivas, em que não é possível estabelecer uma relação de adição e sim no princípio multiplicativo. (NUNES et al., 2005).

De acordo com Nunes et al. (2005, p. 123), "a lógica das quantidades extensivas baseia-se, como vimos, na relação parte-todo: portanto, no raciocínio aditivo. A lógica das quantidades intensivas baseia-se numa relação entre duas quantidades: portanto, no raciocínio multiplicativo". Ainda, facilmente pode-se medir quantidades extensivas discretas, como na situação: numa fruteira encontram-se quatro maçãs e seis laranjas. Qual a fração que representa a quantidade de maçãs da fruteira? 0 mesmo não acontece com as quantidades extensivas contínuas: uma pizza circular foi dividida em oito partes iguais. Uma pessoa comeu três pedaços da pizza. Que fração da pizza ela comeu?

As situações apresentam a mesma natureza (frutas e pizza, respectivamente) e estão baseadas na lógica parte-todo (princípio aditivo). Quando se faz uso de unidades de mesma natureza, como 
nos dois exemplos anteriores, fica mais fácil aos participantes explorarem a lógica das quantidades extensivas. Para Nunes et al. (2005, p. 135), "uma medida de uma quantidade extensiva expressa 0 número de unidades que correspondem ao todo medido", assim como foi verificado nos casos das maçãs e laranjas na fruteira e dos pedaços de pizza. Observa-se agora a seguinte situação:

Vamos organizar uma festa para os garotos da classe e outra separada para as garotas. Na classe há 12 garotas e 8 garotos. Para cada festa, compramos 24 bombons. Em cada festa, os bombons vão ser distribuídos igualmente entre os participantes. Os garotos e as garotas vão ganhar o mesmo número de bombons? Por quê? (NUNES et al., 2005, p. 143).

0 problema remete a quantidades discretas (pessoas) e a comparação se dá em relação a duas quantidades muito distintas (pessoas e bombons) e em duas festas diferentes, em que se pretende descobrir a quantidade de bombons para cada grupo de pessoas (garotas e garotos), portanto, tem-se quantidade intensiva.

Podemos distinguir dois tipos de quantidades intensivas. Em algumas delas, as suas unidades diferentes estão combinadas, formando um todo. Por exemplo, quando misturado suco concentrado e água, estamos formando um todo. Nesse caso, podemos descrever a concentração do suco de duas maneiras: 2 copos de suco concentrado para cada copo de água; ou de suco concentrado e de água. (NUNES, et al., 2005, p. 152).

Nota-se, que uma situação que envolve as quantidades intensivas pode ser expressa de duas maneiras: razão ou fração. Porém, nem todas podem ser interpretadas dessa forma, por exemplo, quando falamos " três reais por quilo de laranjas". De acordo com o que propõe Nunes et al. (2005), a fração só pode ser aplicada às quantidades intensivas em situações como dois terços de suco concentrado e um terço de água, e a fração escrita tem dois sentidos: representar uma divisão e indicar quantidades.

No quadro 1, a seguir, apresentamos a relação entre as quantidades (contínuas, discretas, intensivas e extensiva).

Quadro 1 - Relação entre quantidades discretas e contínuas, intensivas e extensivas

\begin{tabular}{|c|l|l|}
\hline Quantidades & \multicolumn{1}{|c|}{ Intensivas } & \multicolumn{1}{c|}{ Extensivas } \\
\hline Contínuas & $\begin{array}{l}\text { No preparo de um suco de laranja foram utilizados 2 copos } \\
\text { de suco concentrado e 1 copo de água. Qual a fração que } \\
\text { representa a quantidade de suco concentrado e de água } \\
\text { nesse preparo? }\end{array}$ & $\begin{array}{l}\text { de uma estrada corresponde a 75 km. Qual a distância da } \\
\text { estrada? }\end{array}$ \\
\hline Discretas & $\begin{array}{l}\text { No preparo de um litro e meio de suco, foram utilizadas 3 } \\
\text { partes de água e 2 partes de polpa de fruta. Qual a fração } \\
\text { que representa a quantidade de água no suco? }\end{array}$ & $\begin{array}{l}\text { Numa fruteira encontram-se 4 maçãs e } 6 \text { laranjas. Qual a } \\
\text { fração que representa a quantidade de maçãs da fruteira? }\end{array}$ \\
\hline
\end{tabular}

Fonte: Construção do autor

0 quadro exposto permite que sejam apresentadas as situações, e o modo com que os professores as resolveram. 


\section{SOLUÇÃO DE PROBLEMAS DE FRAÇÃO}

Reitera-se que neste artigo são exibidas as análises das questões que envolvem quantidades, a partir dos significados de fração parte-todo, medida, quociente e operador multiplicativo.

\section{Parte-todo}

As situações apresentadas na tarefa 01 remetem a quantidades contínuas (suco de laranja) e as relações fracionárias que se realizam nas questões, contemplam o princípio aditivo e, por conseguinte, nas quantidades extensivas em que se expressa o número de unidades que expressam o todo (NUNES et al., 2005).

Quadro 2 - Tarefa 01 parte-todo desenvolvida com os participantes

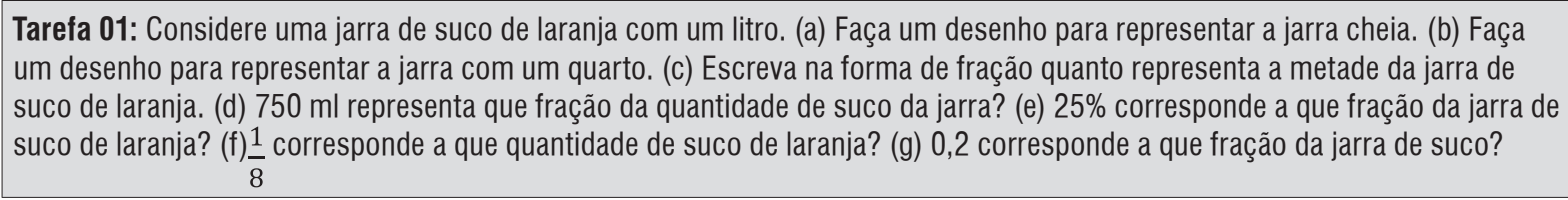

Fonte: Construção do autor

Para responder as questões os participantes utilizaram desenhos, demarcando os limites de suco na jarra. Somente um dos professores aplicou a fração $\left(\frac{1}{1000}\right)$ para representar a quantidade de suco dentro da jarra. Para representar a jarra com um quarto de suco de laranja, doze professores fizerem um desenho e dividiram em quatro partes, aparentemente iguais, destacando uma delas para representar a fração $\frac{1}{4}$. um deles realizou o mesmo procedimento de solução, mas não identificou qual das partes representava a resposta da pergunta.

Oito professores, empregaram corretamente a fração $\frac{1}{2}$ na resolução da questão "c" e dois representaram com frações equivalentes $\left(\frac{2}{4}\right.$ e $\left.\frac{500}{1000}\right)$. Outros quatro não representaram corretamente a resposta, indicando por exemplo $\frac{1}{5}$ e $\frac{1}{4}$. Na questão "d", os participantes deveriam ter compreendido que um litro de suco corresponde à $1.000 \mathrm{ml}$ para resolverem ao que foi solicitado. Cauchy (2018), por exemplo, dividiu $1 \mathrm{l}$ em quatro partes iguais a $250 \mathrm{ml}$ e percebeu que $750 \mathrm{ml}$ corresponde a $\frac{3}{4}$ (quantidades contínuas e de mesma natureza).

Na solução apresentada por Cauchy (2018), fica evidente a utilização do princípio aditivo e a lógica do significado parte-todo, em que o participante percebe que 0 todo corresponde a $1.000 \mathrm{ml}$ e que, na situação, considera-se quatro partes iguais a $250 \mathrm{ml}$. Assim, utiliza-se da soma das partes e nota-se que a fração $\frac{3}{4}$ corresponde a três partes iguais a $250 \mathrm{ml}, 0$ que nos leva ao resultado $(750 \mathrm{ml})$. Percebemos que apenas quatro dos quatorze professores resolveram a situação de maneira correta com a fração $\frac{3}{4}$.

Seis participantes transformaram 1 litro em $1000 \mathrm{ml}$ e realizaram a operação de divisão $(1000 \div 4=250)$, na questão "e", percebendo que $\frac{1}{4}$ da quantidade encontrada corresponde a $250 \mathrm{ml}$, bem como a $25 \%$. Quatro não responderam à questão, dois usaram as frações $\frac{1}{3} \mathrm{e} \frac{1}{2}$, respectivamente, de maneira errada; dois notaram que $25 \%$ da jarra de suco de laranja resulta em 250 ml, mas erraram a representação fracionária. 
Na fração $\frac{1}{8}$, quatro professores perceberam que a quantidade total das partes é 08 e procederam com 0 cálculo da divisão $1000 \div 8=125 \mathrm{ml}$. Assim, entenderam que a fração dada corresponde à quantidade (contínua e extensiva) de $125 \mathrm{ml}$ de suco de laranja. Outros três participantes compreenderam que $11=1000 \mathrm{ml}$ e que cada parte da quantidade do litro corresponde à $100 \mathrm{ml}$, levando-os a concluir que a solução da questão "f" é $800 \mathrm{ml}$. Um outro participante encontrou como resultado $100 \mathrm{ml}$ e percebeu que $\frac{1}{8}$ representa a metade de $\frac{1}{4}\left(\frac{1}{4}\right.$ de $\left.1000 \mathrm{ml}=250 \mathrm{ml}\right)$. Ele fez um desenho que representa a quantidade solicitada na questão, no entanto, cometeu um equívoco ao escrever a resposta. Apenas um participante respondeu que $\frac{1}{8}$ da quantidade de suco de laranja corresponde ao "todo". Em relação à questão "g", quatro professores cometeram equívocos ao usar $\frac{1}{8}$, "meio", $20 \% \mathrm{e}$ uma representação por meio de desenho como frações correspondentes ao decimal 0,2. Ressalta-se que Tales de Mileto (2018) realizou a conversão de registro decimal em percentual $(0,2=20 \%)$, mas não se atentou ao que foi questionado.

A tarefa 02, a seguir é constituída de cinco questões em que se combinaram representações numéricas (percentual, fracionária e decimal) que remetem a quantidades contínuas e extensivas (NUNES et al., 2005), cujas respostas requerem representações na forma de fração, percentual e desenho.

\title{
Quadro 3 - Tarefa 02 parte-todo desenvolvida com os participantes
}

\begin{abstract}
Tarefa 02: Uma pizza circular foi dividida em oito partes iguais. (a) Uma pessoa comeu $25 \%$ da pizza. Que fração da pizza ela comeu? (b) Uma pessoa comeu três pedaços da pizza. Que fração da pizza ela comeu? (c) Uma pessoa comeu 0,125 da pizza Qual a fração correspondente? (d) Faça um desenho que represente $\frac{1}{8}$ da pizza. (e) Sobrou pizza? ( ) Sim ( ) Não. Se sim, que percentual? ..... Que fração?
\end{abstract}

Fonte: Construção do autor

Os professores não tiveram dificuldades em representar a pizza dividida em oito pedaços, aparentemente iguais. Na questão "a", sete professores resolveram corretamente a questão por meio das frações $\frac{1}{4} \mathrm{e} \frac{2}{8}$, seis responderam de maneiras equivocadas $\left(\frac{1}{7} ; \frac{1}{3} ; \frac{2}{0,2} ; 0,25, \frac{1}{2} e \frac{4}{8}\right)$ e um não deixou a questão em branco. Na questão 'b', dez não tiveram dificuldade para representar a quantidade de pizzas que uma pessoa havia comido em relação à quantidade total por meio da fração $\frac{3}{8}$, quatro usaram a noção de proporção entre a quantidade de pizza e pedaços que foram comidos, rêpresentada por $\frac{1}{3}$.

Na questão "c", três professores souberam que a quantidade 0,125 da pizza corresponde à fração $\frac{1}{8}$. Os demais não resolveram o problema: um deles desenhou uma pizza dividida em 8 pedaços e pintou metade de 1 pedaço, cinco usaram as frações $\frac{125}{10}, \frac{2}{8}, \frac{1}{0}$ ? e $\frac{0,125}{8}$ e seis não responderam. No entanto, ao serem solicitados que fizessem um desenho para representar $\frac{1}{8}$ da pizza (questão "d"), a maioria entendeu que a pizza seria dividida em oito partes, mas nem todos destacaram uma das partes. Nove deles responderam de maneira correta, enquanto cinco não solucionaram ao perguntado.

Durante a realização da questão, nove professores perceberam que havia sobrado pizza. No entanto, apenas dois perceberam que a quantidade que havia sobrado corresponde a $25 \%$, e dois professores responderam que a pizza que sobrou pode ser representada pela fração $\frac{1}{4}$ ou $\frac{2}{8}$. Dos que disseram haver sobrado pizza, apenas um respondeu que a fração que representa esta quantidade é $\frac{2}{8}$. Um disse não ter sobrado pizza e quatro não responderam. 


\title{
Medida
}

Esta atividade é composta por duas tarefas, apresentadas em linguagem alfabética e numérica, em que é solicitado que os participantes expliquem como pensaram ou procederam para responder 0 que foi demandado. As respostas remetem a fração ou a quantidades (NUNES et al., 2005) que representam partes ou o todo.

Quadro 4 - Tarefa 01 Medida desenvolvida com os participantes

\begin{abstract}
Tarefa 01: No preparo de um litro de suco foram utilizadas 3 medidas de água e 2 medidas de polpa de fruta. (a) Qual a fração que representa a quantidade de água no suco? (b) Qual a fração que representa a quantidade de polpa de fruta no suco? (c) Qual a quantidade de água no suco? (d) Qual a quantidade de polpa de fruta no suco? (e) Explique como você pensou/procedeu para chegar às repostas.
\end{abstract}

\section{Fonte: Construção do autor}

0 enunciado da tarefa 01 versa sobre a preparação de um suco, utilizando-se uma quantidade de água e outra de polpa de frutas, o que nos remete a quantidades contínuas e intensivas (NUNES et al., 2005), cujas respostas alude à representação fracionária e/ou capacidade.

Observou-se que um participante estabeleceu relação entre as quantidades dos dois componentes (água e polpa) e escreveram as frações $\frac{3}{2}$ (questão "a") e $\frac{2}{3}$ (questão "b"), em que o número 3 está relacionado às medidas de água e 02 às de polpa de fruta. Assim, nota-se que 0 participante não compreendeu que o todo é composto por 05 partes $(3+2=5)$ e, portanto, as representações fracionárias deveriam ser $\frac{3}{5}$ (água) e $\frac{2}{5}$, (polpa de fruta), situação essa que foi percebida por poucos professores. Na questão a, quatro professores solucionaram corretamente com a fração $\frac{3}{5}$, três não responderam e sete utilizaram as frações $\frac{1}{3}, \frac{1}{6}, \frac{3}{2}$ e $\frac{3}{4}$ de maneira errada. Já na questão $b$, observa-se que cinco representaram corretamente ao que foi solicitado por meio da fração $\frac{2}{5}$. Seis professores erraram na solução $\left(\frac{1}{2}, \frac{1}{4} \mathrm{e} \frac{2}{3}\right)$ e três não responderam.

Três participantes entenderam que a quantidade de água no suco é $600 \mathrm{ml}$ e a de polpa de fruta é $400 \mathrm{ml}$, nas questões "c" e "d", respectivamente. Isso porque perceberam que $11=1000 \mathrm{ml}$, e $\frac{3}{5}$ corresponde à $600 \mathrm{ml}[(1000 \div 5) \times 3]$ e $\frac{2}{5}$ à $400 \mathrm{ml}[(1000 \div 5) \times 2]$. Cinco professores não responderam e sete erraram na solução fazendo uso de $3,4, \frac{3}{3}, 750 \mathrm{ml}, \frac{3}{5}$, 1 litro, na questão "c" e 2, 6, $\frac{2}{2}$, $500 \mathrm{ml}, \frac{2}{5}, 2$ medidas e $250 \mathrm{ml}$, na questão "d".

A tarefa 02, a seguir, trata de uma fruteira que contém maçãs e laranjas, cujas respostas relacionam-se à identificação da fração em diferentes representações, ou ainda, que as quantidades sejam indicadas de forma relativa ou absoluta. A atividade requer também que os participantes identifiquem o numerador e 0 denominador de uma fração. Trata-se da indicação de quantidades de natureza distintas (maçãs e laranjas) e que compõem o todo (frutas). Isso nos remete também a quantidades extensivas e discretas (NUNES et al., 2005). 
Quadro 5 - Tarefa 02 Medida desenvolvida com os participantes

\begin{abstract}
Tarefa 02: Numa fruteira, encontram-se 4 maçãs e 6 laranjas. (a) Qual a fração que representa a quantidade de maçãs da fruteira? Que quantidade de frutas representa o numerador da fração? Que quantidade de frutas representa 0 denominador da fração? (b) Qual a fração que representa a quantidade de laranjas da fruteira? Que quantidade de frutas representa 0 numerador da fração? Que quantidade de frutas representa o denominador da fração? (c) Represente na forma percentual a quantidade de maçãs da fruteira. (d) Represente na forma decimal a quantidade de laranjas da fruteira. (e) Explique como você pensou/procedeu para chegar às repostas.
\end{abstract}

Fonte: Construção do autor

Na questão "a", somente um participante não respondeu. Cinco professores escreveram que a fração que representa a quantidade de maçãs na fruteira é $\frac{4}{10}$, e três deles entenderam que a quantidade de frutas que representam numerador e denominador são 4 e 10, respectivamente. A esse respeito, Castro (2018) apontou que "a junção de $4+6=10$, portanto, o inteiro é $10=100 \%$. Sendo que 4 frutas de 10 são $=40 \%, 0,4$ e $\frac{4}{10}$ ". Oito professores não perceberam que a fração que representa a quantidade de frutas na fruteira é $\frac{4}{10}$ e escreveu outros registros fracionários $\left(\frac{4}{1}, \frac{10}{4}, \frac{1}{4}, 10, \frac{4}{4}\right)$. Uma situação semelhante ocorreu na questão "b", em que quatro participantes inferiram que a fração que representa a quantidade de laranjas da fruteira é $\frac{6}{10}$ e que os termos 6 e 10 correspondem ao numerador e ao denominador.

Quando Ihes foi solicitado que representassem na forma percentual a quantidade de maçãs na fruteira (questão "c"), apenas quatro participantes escreveram que seria 40\% e, naturalmente , verificaram a relação $\frac{4}{10}=40 \%$. Em relação à questão "d", seis participantes escreveram que o número decimal que representa a quantidade de laranjas na fruteira seria 0,6. Castro (2018) escreveu "[...] sendo que 6 frutas de 10 são $=60 \%, 0,6$ e $\frac{6}{10}$, isto é, o professor entendeu que $\frac{6}{10}=0,6=60 \%$.

\title{
Quociente
}

Essa atividade é composta por três tarefas em que foi solicitado aos participantes, a resolução dos problemas e a explicação do modo com que refletiram e procederam para resolvê-las, utilizando-se do significado quociente (MERLINI, 2005). 0 Enunciado da tarefa 01, contém representações fracionárias e linguagem natural, lançando mão de transformação de medidas.

\section{Quadro 6 - Tarefa 01 Quociente desenvolvida com os participantes}

\begin{abstract}
Tarefa 01: Considere cada uma das situações a seguir e responda: (a) Ao dividir uma pizza entre 4 (quatro) amigos, com que fração da pizza cada um ficará? (b) Ao dividir duas pizzas entre 4 (quatro) amigos, com que fração da pizza cada um ficará? (c) Ao dividir três pizzas entre 4 (quatro) amigos, com que fração da pizza cada um ficará? (d) Ao dividir quatro pizzas entre 4 (quatro) amigos, com que fração da pizza cada um ficará? (e) Ao dividir cinco pizzas entre 4 (quatro) amigos, com que fração da pizza cada um ficará? (f) Em qual das situações elencadas anteriormente a pessoa comeu maior quantidade de pizza? (g) Explique como você pensou/procedeu para chegar às respostas das questões "a" a "f". (h) Ao dividir uma pizza entre 10 (dez) amigos, com que fração da pizza cada um ficará? (i) Ao dividir uma pizza entre 100 (cem) amigos, com que fração da pizza cada um ficará? (j) No caso dos itens "h" e "i", em que situação o sujeito comeu menor quantidade de pizza? (k) Explique como você pensou/procedeu para chegar às respostas das questões "h", "i" e "j".
\end{abstract}

\section{Fonte: Construção do autor}

A tarefa refere-se a diferentes quantidades de pizza para serem divididas entre uma mesma quantidade de pessoas (quantidade discreta e extensiva), com o intuito de saber com que fração 
da pizza cada um ficaria (questões "a" a "e"). Questiona-se também, em que situação determinado sujeito comeu uma maior quantidade de pizza. Já nas questões "h" e "i", divide-se uma pizza para quantidades diferentes de pessoas assim como, busca-se saber com que fração cada um ficou. Além disso, buscou-se saber também quem comeu uma menor quantidade de pizza.

Para resolver esta tarefa, onze professores recorreram a representações geométricas para ilustrar uma pizza. Responderam que ao dividir a pizza entre os amigos, cada um ficaria com $\frac{1}{4} d a$ quantidade. Silva (2018) fez o desenho circular da pizza dividindo-a em oito partes e destacou duas delas, sendo que $\frac{2}{8}=\frac{1}{4}$ (questão "a"). Cinco professores responderam adequadamente a situação em que se divide duas pizzas para a mesma quantidade de amigos. Sete professores aproveitaram-se também de registros numéricos $\left(\frac{4}{2}, \frac{8}{2}, \frac{2}{8}, 2\right)$ e em língua natural ("cada um com (2) partes", "cada um ficaria com dois pedaços"), como solução da questão "b". Possivelmente, os que encontraram a fração $\frac{2}{8}$ possam ter utilizado o resultado encontrado na questão "a" $\frac{1}{4}$ e realizado 0 cálculo $\frac{1}{4}+\frac{1}{4}=\frac{2}{8}$, no entanto, isso não ficou claro em sua resposta. Para solução da questão "c", cinco participantes perceberam que ao dividir três (03) pizzas para quatro (04) amigos tem-se como resultado a fração $\frac{3}{4}$, outros seis mobilizaram as frações $\frac{12}{4}, \frac{8}{4}, \frac{4}{3}, \frac{3}{12}$ e 0 número 0 (zero) como possível resposta, mas o fizeram de maneira equivocada.

Na divisão de quatro pizzas para quatro amigos (questão "d"), quatro professores responderam que cada amigo ficaria com uma pizza $\left(\frac{4}{4}\right)$, porém, não foi possível verificar o modo com que chegaram a essa resolução. D’Alembert (2018) escreveu: "cada um ficará com 8 pedaços". No entanto, não possível compreender se a quantidade de pedaços apontadas pela participante corresponde a uma pizza inteira.

Destaca-se a solução de Araújo (2018), que dividiu as pizzas em partes iguais e escreveu que, ao dividir cinco pizzas entre quatro amigos, tem-se "1 inteiro e 1/4", na questão "e". Isso s significa dizer que a participante percebeu que cada amigo ficaria com uma pizza inteira e mais $1 / 4$ da quinta $\left(1+\frac{1}{4}\right)$. Dois professores utilizaram a fração $\frac{4}{5}$ em suas respectivas soluções, provavelmente por não terem compreendido 0 enunciado da questão. Apenas três professores compreenderam que das situações de "a" a "e", a pessoa que comeu mais pizzas foi aquela apresentada na questão "e", em que comeram uma pizza inteira e $1 / 4$ da outra.

Em relação às questões " $h$ " e "i", oito participantes entenderam que as soluções seriam $\frac{1}{10}$ (questão "h") e $\frac{1}{100}$ (questão “i”), e quatro não conseguiram resolver de maneira correta ou deixaram de responder. Ao serem questionados em qual dessas situações a pessoa comeria a menor quantidade de pizza, seis deles responderam ser na segunda situação.

Quadro 7 - Tarefa 02 Quociente desenvolvida com os participantes

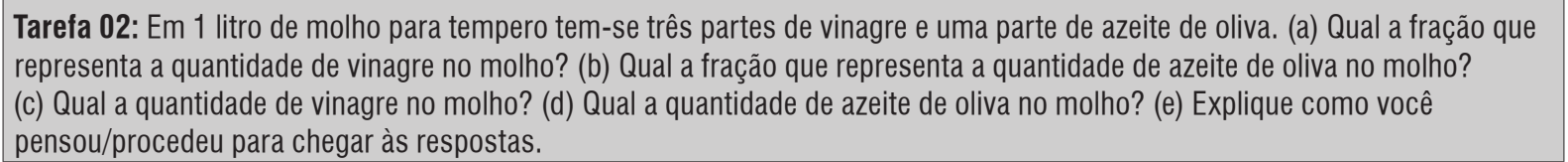

Fonte: Construção do autor

Essa tarefa trata de dois ingredientes (vinagre e azeite de oliva), que compõem um litro de moIho para tempero, o que nos remete a quantidades consideradas (vinagre e azeite de oliva) intensivas e contínuas (NUNES et al., 2005). Os itens apresentados referem-se a representações fracionárias e 
tem por objetivo saber a fração que representa as quantidades (vinagre e azeite de oliva) no molho, e a quantidade de cada ingrediente no molho para tempero.

Somente dois professores conseguiram solucionar as situações apresentadas nas questões de "a" a "d". Évariste Galois (2018) compreendeu que "1l = 1000 cada parte dos ingredientes representa $\frac{1}{4}$, tem-se então $\frac{1}{4}$ de azeite e $\frac{3}{4}$ de vinagre. $1000 \div 4=250$ que corresponde a cada parte em ml". Um participante respondeu as questões fazendo uso de registro de representação semiótica decimal, escrevendo 0,75 (questão "a") e 0,25 (questão "b"). Tratam-se de valores equivalentes às frações solicitadas $\left(\frac{3}{4} \mathrm{e} \frac{1}{4}\right)$, mas não resolve às questões. Onze participantes não responderam de maneira adequada ou não responderam, isto é, cometeram erros nas soluções, indicando, por exemplo, frações como $\frac{1}{3}, \frac{3}{1}, \frac{3}{2} \mathrm{e} \frac{3}{10}$ as quais representariam a quantidade de vinagre no molho $\mathrm{e} \frac{1}{3} \mathrm{e} \frac{1}{1}$ para representar a quantidade de azeite de oliva.

\section{Operador multiplicativo}

Nesse bloco, é analisada uma atividade organizada em cinco tarefas, em que foi solicitado à 15 participantes que explicassem como pensaram ou procederam para solucionar cada uma das questões.

Quadro 8 - Tarefa 01 Operador Multiplicativo desenvolvida com os participantes

Tarefa 01: Calcule: (a) $\frac{3}{5}$ de 355 , explique como você pensou/procedeu para chegar às respostas. (b) de 2500 pessoas.
Explique como você pensou/procedeu para chegar às respostas. (c) $\frac{2}{5}$ de 3750 metros. Explique como você pensou/procedeu
para chegar às respostas.

Fonte: Construção do autor

Solicitou-se aos participantes que calculassem a fração correspondente a um todo. Na questão "a", apresenta-se a informação na forma de fração $\left(\frac{3}{5}\right)$, em que é requerido que o participante calcule a quantidade relativa à fração dada, considerando-se um todo numérico (355). Na questão "b", apresentou-se a representação numérica percentual (40\%), cujo todo (2500) refere-se a pessoas, portanto, trata-se de quantidade discreta (NUNES et al., 2005), em que é demandado que os participantes encontrem a quantidade de pessoas referentes à fração dada. A questão "c" aponta as mesmas características da questão "a", no entanto, o todo se refere a medidas de comprimento (metros), 0 que caracteriza uma quantidade contínua.

Na questão "a" percebemos que cinco professores (05) estabeleceram relação entre as partes $\left(\frac{3}{5}\right)$ e 0 todo (355), e responderam que o resultado da operação seria 213. Para isso, empregaram a divisão do todo pela quantidade total, (05) das partes $[(355 \div 5) \times 3]=[71 \times 3]=213)$. Almeida (2018) registrou: "multipliquei o numerador com o valor e em seguida dividi pelo denominador", obtendo como resultado 213 . Em termos matemáticos, realizou-se a operação: $(3 \times 355) \div 5=1065 \div 5=213$. Laplace (2018), explicou: "implica em tirar três quintos de 355, o que na prática podemos multiplicar o numerador 3 por 355 e dividir o produto por 5 . Outra forma seria, dividir 355 pelo denominador $5 \mathrm{e}$ na sequência multiplicar o quociente por 3 (numerador)".

Para solucionar a questão "b", sete participantes usaram de: (a) $(2500 \times 40) \div 100=100000 \div$ $100=1000$; (b) $(2500 \div 100) \times 40=25 \times 40=1000$; (c) Encontrar $10 \%$ de 2500 (250) e multiplicar 
por 4. "Uma das maneiras: implica em tirar quarenta por cento de dois mil e quinhentos, na prática significa multiplicar o numerador pelo os 2500 e na sequência dividi-lo por 100" (LAPLACE, 2018). Já Barros (2018), considerou que "para chegar a resposta $1^{\circ}$ calculamos $\frac{2500}{100}$ e depois multiplicamos o produto pela porcentagem". Com essas operações, é possível chegar ao resultado pretendido. Na questão "c", os professores aplicaram os mesmos procedimentos adotados na questão "a", incluindo erros e acertos, mas apenas cinco professores responderam de maneira correta.

\section{Quadro 9 - Tarefa 02 Operador Multiplicativo desenvolvida com os participantes}

Tarefa 02: Marcos tinha uma coleção de 30 figurinhas e deu a seu amigo Adílio $\frac{2}{3}$ dessa coleção. Com quantas figurinhas Marcos ficou? Explique como você pensou/procedeu para chegar às respostas.

\section{Fonte: Construção do autor}

A tarefa 02 possui um enunciado de um problema em que foi apresentada a quantidade total de uma coleção (30 figurinhas) e solicitou-se que os participantes indicassem a quantidade de figurinhas que restou após o empréstimo de uma fração $\frac{2}{3}$ da coleção. Trata-se de um enunciado cuja coleção é constituída de quantidades discretas (NUNES et al., 2005).

Oito professores perceberam que 0 todo é representado pela quantidade 30 e que $\frac{2}{3}$ representa parte dessa quantidade, mas dez deles não se atentaram para o fato de que Marcos havia doado ao seu amigo Adílio $\frac{2}{3}$ das figurinhas, e a questão pergunta com que quantidade Marcos ficou. Cinco participantes que responderam a esse bloco realizaram solução semelhante a $(30 \div 3) \mathrm{X} 2=10 \mathrm{X}$ $2=20$ ou $(2 \times 30) \div 3=60 \div 3=20$, afirmando, erroneamente, que Marcos havia ficado com 20 figurinhas. Barros (2018) destacou: "para chegarmos a conclusão usei a operação matemática da subtração calculando a diferença. Ficou com 10 figurinhas", após ter entendido que cada parte corresponde a 10 figurinhas e que Adílio havia ganhado 20 figurinhas de Marcos.

Quadro 10 - Tarefa 03 Operador Multiplicativo desenvolvida com os participantes

Tarefa 03: Letícia tem uma coleção de 12 bonecas e emprestou a sua amiga $\frac{2}{6}$ dessa coleção. Quantas bonecas Letícia emprestou? Explique como você pensou/procedeu para chegar às respostas.

\section{Fonte: Construção do autor}

Apresenta-se um todo discreto (12 bonecas) de uma coleção da qual se empresta uma fração $\frac{2}{6}$ e solicita-se que o participante responda que quantidade da coleção foi emprestada.

Uma possível solução consiste na divisão do todo da coleção (12) pelo todo da fração (6), encontrando, dessa forma, o valor do operador multiplicativo (2), que ao estabelecer relação com a parte da fração tomada (2) obtém-se o valor correspondente às bonecas emprestadas (4). Os participantes também podiam fazer uso da fração equivalente $\left(\frac{1}{3}\right)$ e estabelecer relação do todo da coleção de bonecas (12) com o todo da fração (3), chegando assim, ao resultado da quantidade de bonecas emprestadas (4). Provavelmente, os participantes não efetuaram a simplificação da fração $\frac{2}{6}$.

Para solucionarem esta tarefa, seis participantes apresentaram como solução a divisão do todo da coleção de bonecas (12) pela quantidade total das partes (06) da fração $\frac{2}{6}$ e encontraram 
o operador multiplicativo 2, que corresponde a $\frac{1}{6}$ da coleção. Posteriormente, realizaram a multiplicação do número obtido (2) com a parte da fração tomada (2) e obtiveram o resultado 4, que corresponde à quantidade de bonecas emprestadas. Três professores erraram a solução, enquanto sete não responderam.

\section{Quadro 11 - Tarefa 04 Operador Multiplicativo desenvolvida com os participantes}

Tarefa 04: de uma estrada corresponde a $75 \mathrm{~km}$. Qual a distância da estrada? Explique como você pensou/procedeu para chegar às respostas.

\section{Fonte: Construção do autor}

A tarefa do quadro acima, demonstra uma quantidade contínua e extensiva, cuja parte (75 km) representa uma fração $\left(\frac{3}{5}\right)$, foi solicitado aos participantes que encontrassem o todo. Isso significa que foi disponibilizado o valor absoluto da fração apresentada e se pediu 0 valor absoluto de toda a quantidade da fração.

Um participante utilizou a relação $(75 \div 5) \times 3=15 \times 3=45$. Dois encontraram resultados diferentes (25km e $75.000 \mathrm{~m})$, mas não explicaram como procederam. No entanto, os dados revelaram que cinco participantes responderam a esse bloco, compreendendo "uma das maneiras é: divide-se 0 todo $75 \mathrm{~km}$ pelo numerador da fração 3. Na Sequência, multiplica-se o quociente pelo denominador 5 e têm-se a distância total da estrada" (LAPLACE, 2018), que corresponde à 125km.

Quadro 12 - Tarefa 05 Operador Multiplicativo desenvolvida com os participantes

Tarefa 05: Vovó comprou um quilograma de açúcar para fazer bolo. Foram utilizados: 25\% para fazer a massa; 0,2 kg para o preparo do recheio; $\frac{2}{20}$ do açúcar para a produção da cobertura. (a) Qual a quantidade de açúcar utilizado para fazer a massa? (b) Qual a quantidade de açúcar utilizado para fazer o recheio? (c) Qual a quantidade de açúcar utilizado para fazer a cobertura? (d) Qual a quantidade de açúcar utilizada para fazer o bolo? (e) Qual a quantidade de açúcar que restou? (f) Que fração do quilograma de açúcar restou? (g) Explique como você pensou/procedeu para chegar às respostas.

Fonte: Construção do autor

Essa tarefa diz respeito a quantidades apresentadas em números relativos (25\%; 0,2 e 25\%; 0,2 $\left.\mathrm{e} \frac{2}{20}\right)$ pertencente a uma receita de bolo, em que a quantidade de partes dos componentes indicam quantidades contínuas, foi apresentada em registros numéricos (percentual, decimal e fracionário). Ao adicionar leite, açúcar, e farinha, por exemplo, para produzir a massa do bolo, tem-se uma mistura homogênea, 0 que denota que se trata de uma quantidade contínua e intensiva. 0 enunciado apresenta a quantidade total (1kg de açúcar), da qual foram utilizadas frações para preparar, respectivamente, a massa, o recheio e a cobertura, em que a pergunta recai sobre a quantidade e a fração restante.

Verificou-se que oito professores entenderam que a quantidade de açúcar utilizado para fazer a massa do bolo é $250 \mathrm{~g}$, isso se deu porque eles compreenderam que $25 \%$ de $1 \mathrm{~kg}=1000 \mathrm{~g}$ corresponde a $250 \mathrm{~g}$. Nascimento (2018) assentou como procedeu para resolver a questão: "procurei entender as informações que 0 enunciado me deu. Fiz cálculos mentais lógicos de porcentagem $25 \%$ 
de $1000 \mathrm{~g}=250$. Adição dos números encontrados". Somente três dos participantes que responderam a esse bloco entenderam que a quantidade de açúcar para o recheio seria $200 \mathrm{~g}$.

Quatro professores encontraram o resultado $(100 \mathrm{~g})$, que corresponde à quantidade de açúcar utilizada para fazer a cobertura do bolo, e dois não acertaram a solução e entenderam que, possivelmente, os resultados seriam (4 e 200g). Em relação à questão "d", esperava-se que os participantes que responderam esse bloco realizassem a soma das quantidades encontradas nas questões e chegassem à solução. No entanto, isso foi realizado apenas por três professores, os quais chegaram à conclusão de que a quantidade de açúcar utilizada para fazer o bolo foi $550 \mathrm{~g}$.

Apenas dois professores conseguiram perceber que, se na questão "d" verificou-se que foram usados $550 \mathrm{~g}$ para fazer o bolo, restariam $450 \mathrm{~g}$ (questão "e"). Na questão "f", somente um professor encontrou a solução e escreveu a fração $\frac{450}{1000}$ corretamente, enquanto que os demais participantes não obtiveram sucesso ao considerar as frações $\left(\frac{1}{2}, \frac{2}{3}, \frac{550}{1000} \mathrm{e} \frac{45}{10}\right)$ como a fração do quilograma de açúcar que restou.

\section{RESULTADOS E CONCLUSÕES}

De acordo com o que foi observado, verificou-se que o objetivo proposto foi alcançado uma vez que os participantes apresentaram facilidade em resolver situações que envolvem o significado parte-todo, seja na comparação de quantidades contínuas ou discretas. Todavia , notou-se que existiu uma "preferência" em fazer uso de quantidades contínuas na resolução das situações apresentadas, especialmente, recorrendo ao desenho geométrico (contínuo) para responderem às questões.

Nesse sentido, notou-se que há uma tendência dos professores em fazerem uso durante sua atividade docente, do significado parte-todo e de quantidades contínuas nas aulas sobre fração, 0 que pode direcionar os estudantes a uma aprendizagem limitada. Isto porque existem outros significados de fração (MERLINI, 2005; SILVA, 2005) e características de quantidades que são necessárias nestes processos.

Ademais, percebe-se que os professores utilizam principalmente representações geométricas (pizzas e retângulos, especialmente) na realização das aulas sobre fração. No caso de fração, por exemplo, a representação 0,5 é possível a partir de outras representações que remetem a mesma quantidade, seja ela contínua, discreta, intensiva ou extensiva: língua natural (zero vírgula cinco, cinco décimos), fração $\left(\frac{5}{10}=\frac{1}{2}\right)$, porcentagem (50\%), representações gráficas e geométricas, envolvendo as quantidades contínuas e discretas, bem como as intensivas e extensivas. Constata-se que os participantes, recorrem, em muitos casos, às representações geométricas e a divisões entre os numeradores e denominadores, cujo objetivo é encontrar a solução do problema. Quando as situações apresentam uma quantidade na forma fracionária e pede que façam um desenho que a represente, muitos professores não apresentam dificuldades. Do mesmo modo, conseguem encontrar a fração de uma quantidade apresentada inicialmente na forma de desenho.

Em relação ao significado medidas, verificou-se que nove (09), dos quinze participantes que receberam esta atividade, tiveram dificuldades em reconhecer os termos de uma fração (numerador e denominador) e em representar as quantidades de frutas (maçãs e laranjas) em relação à quantidade de frutas da fruteira, por meio da fração. Poucos procederam corretamente com a resolução das questões ou explicaram como pensaram para chegar às respostas.

$\mathrm{Na}$ atividade com significado quociente, foi apurado s que os participantes têm maior facilidade para resolver situações em que o numerador é menor que o denominador (frações próprias). 
No entanto, quando se trata de frações que são impróprias, os professores apresentam dificuldades nas soluções.

Em relação à atividade que trata do significado operador multiplicativo, verificamos na tarefa 01 , que a maioria dos participantes (incluindo os que erraram e àqueles que não resolveram) desse bloco tiveram dificuldades para resolver as questões "a" e "c", já que 66,67\% professores não conseguiram perceber que as frações $\left(\frac{3}{5} \mathrm{e} \frac{2}{5}\right)$ representavam partes de um todo, 355 e 3750 metros, respectivamente. Na questão "b", os participantes não mostraram dificuldades para solucionar a questão. Eles recorreram ao uso da conversão de quantidades em forma percentual $(40 \%)$ em fracionário $\left(\frac{40}{100}\right) \mathrm{e}$ mobilizaram as operações de multiplicação e divisão para encontrar o resultado (1000).

\section{REFERÊNCIAS}

ARAÚJO, Maria Izabel Lopes de. Objeto de Aprendizagem: um estudo sobre o desempenho dos alunos na interpretação da Função Quadrática. Salvador: 2009. Dissertação (Mestrado em Modelagem Computacional e Tecnologia Industrial) Sistema FIEB, SENAI-CIMATEC.

BESSA, Marcio Leite de. Concepções e práticas de professores sobre 0 Ensino e a Aprendizagem e uma Intervenção intencionalmente planejada no Ensino de Frações, por meio da Resolução de Problemas em um $5^{0}$ Ano do Ensino Fundamental. Brasília, 2007. Dissertação (Mestrado em Educação). Universidade Católica de Brasília. $163 f$.

BRASIL. Secretaria de Educação Fundamental. Parâmetros curriculares nacionais: matemática. Secretaria de Educação Fundamental. Brasília: MEC/SEF, 1997. 142p.

CARVALHO, Euvaldo de Souza. Sequência Didática: uma proposta para o ensino do conceito de fração. Arraias, 2017. Dissertação (Mestrado Profissional em Matemática em Rede Nacional). Universidade Federal do Tocantins. 103 f.

CERVANTES, Patricia de Barros Monteiro. Uma formação continuada sobre frações. São Paulo, 2011. Dissertação (Mestrado em Educação Matemática). Universidade Bandeirante de São Paulo. 86f.

LIMA, Rafael Pontes. 0 ensino e a aprendizagem significativa das operações com frações: Sequência didática e 0 uso de tecnologias digitais para alunos do Ensino Fundamental II. Programa de Pós-Graduação em Educação em Ciências e Matemática da Rede Amazônica de Educação em Ciências e Matemática (REAMEC), Pólo Universidade Federal do Pará / Belém: [s,n], 2014. 232f.

MERLINI, Vera Lúcia. 0 conceito de fração em seus diferentes significados: um estudo diagnóstico com alunos de $5^{a}$ e $6^{a}$ séries do ensino fundamental. Dissertação (Mestrado em Educação Matemática). Pontifícia Universidade Católica, São Paulo, 2005.

NUNES, Terezinha et al. Educação Matemática 1: números e operações numéricas. São Paulo: Cortez, 2005.

PINHEIRO, Maria Gracilene de Carvalho. Formação de Professores dos Anos Iniciais: conhecimento profissional docente ao explorar a introduçãa do conceito de fração. 204f. São Paulo, 2014. Dissertação (Mestrado em Educação Matemática). Universidade Anhanguera de São Paulo, 2014

SCHASTAI, Marta Burda; FARIAS, Elizabeth Regina Streisky de; SILVA, Sani de Carvalho Rutz da. Formação de Professores e o Ensino de Frações nos Anos Iniciais. 1. ed. Curitiba: Appris, 2017. v. 1. 193p 
SILVA, Maria José Ferreira da. Investigando saberes de professores do Ensino Fundamental com enfoque em números fracionários para a quinta série. 2005. Tese (Doutorado em Educação Matemática). Pontifícia Universidade Católica de São Paulo.

SILVA, Maria do Socorro Lucinio da Cruz. Concepções e práticas de professores do Ensino Fundamental sobre 0 ensino de frações: um estudo em escolas de Cuiabá. 2013. 164f. Dissertação (Mestrado em Educação). Universidade Federal de Mato Grosso, Cuiabá, 2013.

SILVEIRA, Denise Tolfo; CÓRDOVA, Fernanda Peixoto. A pesquisa científica. In: GERHARDT, Tatiana Engel; SILVEIRA, Denise Tolfo. Métodos de pesquisa. UAB/UFRGS e SEAD/UFRGS. Porto Alegre: Editora da UFRGS, 2009.

TARDIF, Maurice. Saberes docentes e formação profissional. 17.ed. Petrópolis, RJ: Vozes, 2014.

RECEBIDO EM: 14 abr. 2020

CONCLUÍDO EM: 24 ago. 2020 
